\title{
Expression of the TSLC1 Adhesion Molecule in Pulmonary Epithelium and Its Down-Regulation in Pulmonary Adenocarcinoma Other than Bronchioloalveolar Carcinoma
}

\author{
Akihiko Ito, Morihito Okada, Kazuya Uchino, Tomohiko Wakayama, Yu-ichiro Koma, \\ Shoichi Iseki, Noriaki Tsubota, Yutaka Okita, and Yukihiko Kitamura \\ Department of Pathology (Al, Yu-iK, YukK), Osaka University Medical School, Suita, Osaka, Department of Thoracic \\ Surgery (MO, KU, NT), Hyogo Medical Center for Adults, Akashi, Hyogo, Department of Histology and Embryology \\ (TW, SI), Graduate School of Medical Science, Kanazawa University, Kanazawa, Ishikawa, and Department of \\ Cardiothoracic Surgery (KU, YO), Kobe University School of Medicine, Kobe, Hyogo, Japan.
}

\begin{abstract}
SUMMARY: TSLC1 (tumor suppressor in lung cancer-1) is an adhesion molecule of the Ig superfamily that binds homophilically and mediates cell-cell interactions. Originally, TSLC1 was cloned as a candidate tumor suppressor from the genomic region that frequently exhibits loss of heterogeneity in human non-small-cell lung cancer (NSCLC). However, there have been no studies on TSLC1 expression in normal lungs or NSCLC. Here we show that pulmonary epithelial cells express TSLC1 and its expression levels are often decreased or lost in primary pulmonary adenocarcinoma, a major histologic type of NSCLC. Immunohistochemistry revealed that TSLC1 was localized at cell-cell boundaries of all columnar epithelial cells in mouse embryonic lungs of 10.5 and 13 days postcoitus. Similar staining patterns were observed in bronchiolar and alveolar epithelial cells of adult human lungs, suggesting a physiologic role for TSLC1 in interactions of these cells. Next we performed Western blot analyses of TSLC1 in 47 primary pulmonary adenocarcinomas and judged each tumor as either decreased or nondecreased by comparing TSLC1 expression levels of the tumor with the levels of normal lungs. The expression profiles had a significant relation to histologic subtypes but not to other clinicopathologic parameters. Sixteen bronchioloalveolar carcinomas (BACs) were all judged nondecreased, while 19 of 31 (63\%) adenocarcinomas other than BAC were judged decreased $(p<0.0001)$. Immunohistochemistry of tumors judged nondecreased revealed that not only BAC cells but also tumor cells in lepidic growth components of adenocarcinomas other than BAC expressed TSLC1 on their lateral plasma membranes. These tumor cells are considered less invasive because they proliferate in a lepidic growth pattern along alveolar walls. Thus, the present results not only support the hypothesis that TSLC1 is a tumor suppressor of NSCLC but also suggest that preserved integrity of TSLC1 may contribute to less invasive phenotypes of lepidic growth tumor cells. (Lab Invest 2003, 83:1175-1183).
\end{abstract}

$T$ SLC1 (tumor suppressor in lung cancer-1) is a recently identified member of the Ig superfamily (Kuramochi et al, 2001; Masuda et al, 2002). Its mouse orthologue is SgIGSF (spermatogenic Ig superfamily), which was cloned from adult mouse testes (Wakayama et al, 2001). The two proteins have $98 \%$ amino acid identity with each other (Fukami et al, 2002), and both have an extracellular domain with significant homology to NCAM-1 (neural cell adhesion molecule-1) and NCAM-2. They also bear a motif sequence in their intracellular domains that putatively

\section{DOI: 10.1097/01.LAB.0000081391.28136.80}

Received April 13, 2003.

This work was supported by grants from the Ministry of Education, Culture, Sports, Science and Technology of Japan; the Osaka Cancer Society; the Sagawa Foundation for Promotion of Cancer Research; the Naito Foundation; and the Japanese Association for Metastasis Research.

Address reprint requests to: Dr. Akihiko Ito, Department of Pathology, Osaka University Medical School, 2-2 Yamada-oka, Suita, Osaka 5650871, Japan.E-mail: aito@patho.med.osaka-u.ac.jp. connects to the actin cytoskeleton (Yageta et al, 2002). Consistent with these structural features, recent studies of Masuda et al (2002) and of our own (Ito et al, 2003) have shown that TSLC1 and SgIGSF mediate intercellular adhesion. Both proteins bind homophilically and, at least, SgIGSF is also used as a heterophilic adhesion molecule by particular cells (Ito et al, 2003; Wakayama et al, 2003).

TSLC1 was named after its original cloning from the region of chromosome 11q23.2, where loss of heterozygosity is frequently found in human non-smallcell lung cancer (NSCLC) (Kuramochi et al, 2001). Murakami and colleagues (2002) demonstrated that TSLC1 could function as a tumor suppressor in the mouse model using lung cancer cell lines. TSLC1 strongly suppresses in vivo tumor growth and metastasis, although it neither suppresses in vitro cell growth nor induces apoptosis or cellular senescence (Kuramochi et al, 2001; Yageta et al, 2002). In addition TSLC1 expression is reduced or lost in various lung cancer cell lines due to hypermethylation of the TSLC1 
gene promoter (Kuramochi et al, 2001). In spite of these intensive studies, it remains unclear what relationships exist between the two aspects of TSLC1, an adhesion molecule and a tumor suppressor. Moreover, there are no reports that examined TSLC1 expression in human primary NSCLC or normal lung tissues.

Adenocarcinoma is a major histologic type of NSCLC and is further classified into five subtypes: acinar, papillary, bronchioloalveolar carcinoma (BAC), solid, and adenocarcinoma with mixed subtypes (Travis et al, 1999). BAC is defined by a unique growth pattern of well-differentiated cuboidal tumor cells along intact alveolar walls, ie, lepidic growth. In addition, BAC is clinically distinguished from other types of adenocarcinomas by a better outcome of surgical treatment (Breathnach et al, 1999; Grover and Piantadosi, 1989; Kuriyama et al, 1999; Kwiatkowski et al, 1998). Adenocarcinomas other than BAC often contain lepidic growth components peripherally, where tumor cells proliferate in lepidic growth pattern as do BAC cells (Kumaki et al, 2001; Silver and Askin, 1997). Interestingly, pulmonary adenocarcinomas with larger areas of lepidic growth components manifest better prognoses (Kumaki et al, 2001; Yokose et al, 2000). Adenocarcinoma cells showing lepidic growth seem to be less malignant.

In the present study, we firstly examined TSLC1 expression in the embryonic and adult lung by immunohistochemistry and found pulmonary epithelial cells primarily expressed the TSLC1 protein on their lateral plasma membranes. We next examined, by Western blotting, expression levels of TSLC1 in pulmonary adenocarcinomas of various pathologic stages and histologic subtypes, and found that TSLC1 expression was frequently reduced or lost in adenocarcinomas other than BAC.

\section{Results}

\section{Expression of TSLC1 in Normal Lungs}

We firstly examined TSLC1 expression in the lung tissues at various ages by Western blot analyses using a polyclonal antibody raised against the C-terminal peptide of TSLC1 (Ito et al, 2003; Wakayama et al, 2003). In the embryonic lungs, TSLC1 expression was detectable as early as 13 days postcoitus (pc) (Fig. 1). It markedly increased at 15 days pc and gradually decreased toward the time of birth (Fig. 1). After birth, protein levels of TSLC1 increased again and reached a peak on the 10th day, with a slight decline in adulthood (Fig. 1).

In addition to the expression level, we noticed that mobility size of the TSLC1 protein changed with age. As shown in Figure 1 (left panel), TSLC1 proteins migrated faster on polyacrylamide gels as mice aged. Mobility size of the proteins ranged from 80 to $110 \mathrm{kd}$, and some TSLC1-specific bands were smears larger than 10-kd wide. These results were reminiscent of our previous observations that TSLC1 is a glycoprotein and the extent of its glycosylation is regulated

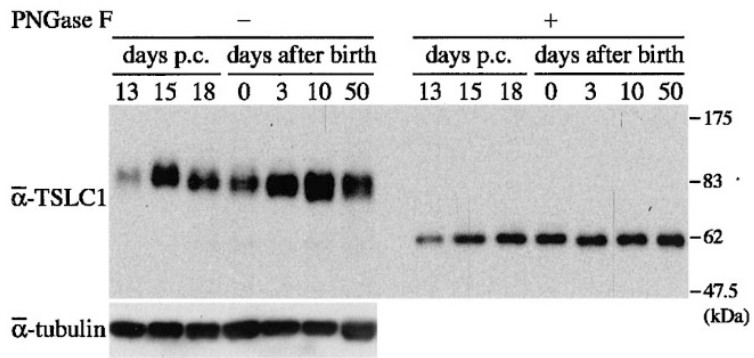

\section{Figure 1.}

Western blot analyses of TSLC1 in mouse lung tissues at various ages. In the left panel, protein samples were prepared from the lung tissues of mice of the indicated ages, subjected to electrophoresis on a $10 \%$ SDS-polyacrylamide gel, and blotted with the anti-TSLC1 antibody. After stripping, the blot was probed again with the anti- $\alpha$-tubulin antibody to indicate the total amount of proteins loaded per lane. In the right panel, the protein samples were treated with peptide $\mathrm{N}$-glycocidase $\mathrm{F}$ (PNGase $\mathrm{F}$ ) before they were blotted with the anti-TSLC1 antibody.

developmentally in testes (Wakayama et al, 2003). Protein samples from the lung tissues were incubated with peptide $N$-glycocidase $\mathrm{F}$ (PNGase F), an amidase that hydrolyzes $N$-glycan chains from glycoproteins, and were then blotted with the anti-TSLC1 antibody. The immunoreactive signals at all ages examined were detected as a sharp band at a reduced size of $\sim 60 \mathrm{kd}$ (Fig. 1, right panel). The extent of glycosylation of TSLC1 appeared to be regulated developmentally in lungs.

We next examined TSLC1 expression in mouse embryonic lungs by immunohistochemistry using the anti-TSLC1 antibody. Because the lung rudiments appear by 10 days pc (Kaufman, 1992), we examined mouse embryos of $10.5,13,15$, and 18 days pc. In the lung buds at 10.5 and 13 days pc, the TSLC1 signals were detectable at cell-cell boundaries of all columnar epithelial cells (Fig. 2, A and B). In the lungs of 15 days pc embryos, epithelial lining gave rise to two architectures, bronchi and bronchioles. All bronchiolar epithelial cells were strongly positive for TSLC1 as well (Fig. 2C). In contrast, TSLC1 signal intensity was weak in bronchial epithelial cells, some of which were negative for TSLC1 (Fig. 2C). This staining pattern was quite similar to that of E-cadherin, a well-known intercellular adhesion molecule, with the exception that signals for E-cadherin in bronchial epithelial cells were as strong as the signals in bronchiolar epithelial cells (Fig. 2D). At 18 days pc, another architecture was seen, the alveoli. Bronchiolar epithelial cells were still positive for TSLC1, while cuboidal cells that line the alveoli were not always positive (Fig. 2E). Staining pattern of the bronchial epithelial cells was similar to that of 15 days pc embryos (Fig. 2, C and F). Cells making up blood vessels were negative for TSLC1 in the embryonic lung (Fig. 2F).

In adult human lungs, signals specific for TSLC1 were detected primarily on the lateral plasma membranes of bronchiolar and alveolar epithelial cells (Fig. 2, $\mathrm{G}$ and $\mathrm{H}$ ). Staining pattern of bronchial epithelial cells was similar to that of 15 and 18 days pc embryos as shown in Figure 2, C and F: Some bronchial epithelial cells were weakly positive for TSLC1 but 


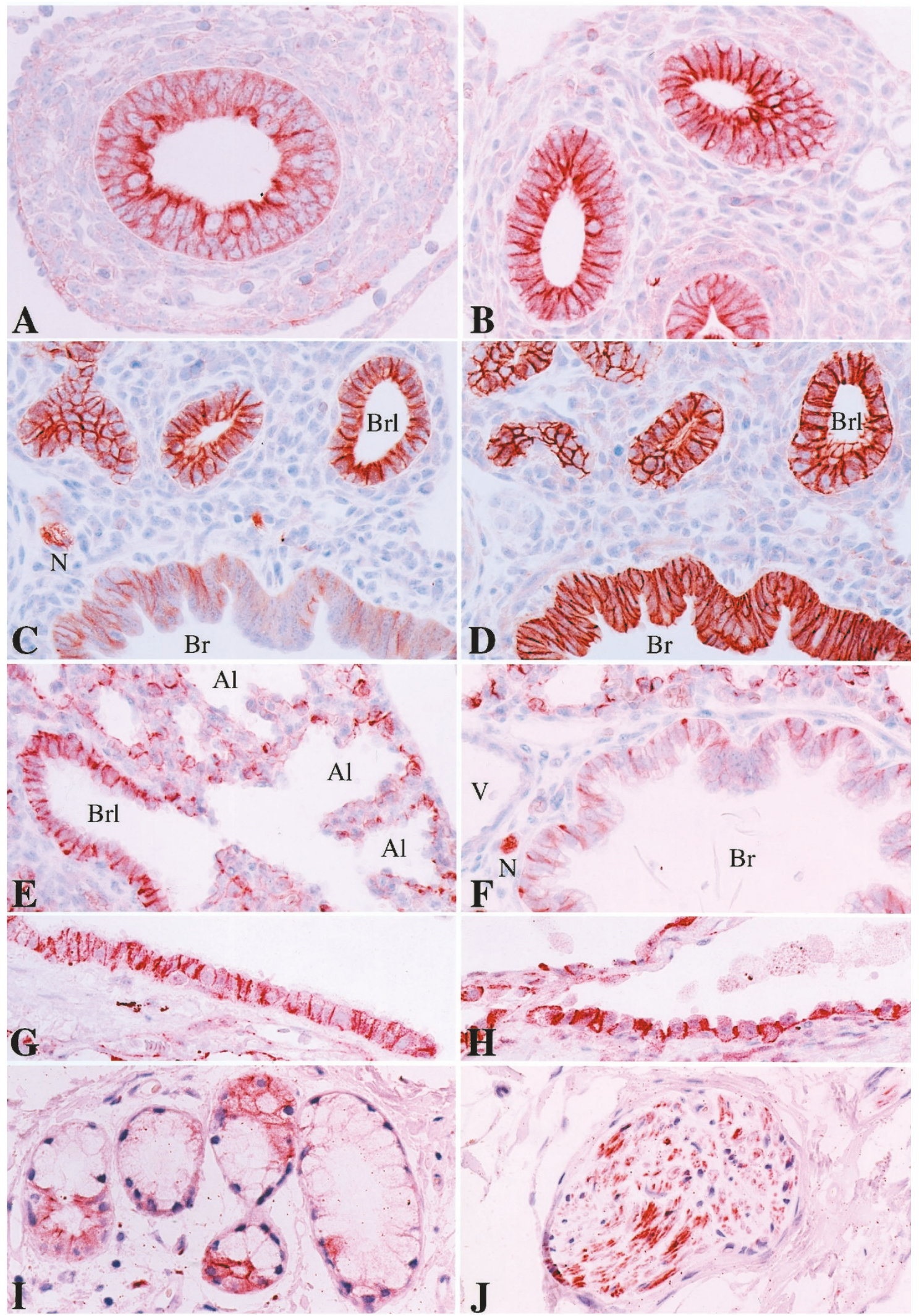

Figure 2.

Immunohistochemical staining of TSLC1 in mouse and human lung tissues. (A to F) Sections of mouse embryonic lungs of 10.5 (A), 13 (B), 15 (C and D, serial sections), and 18 (E and F) days postcoitus were reacted with the anti-TSLC1 (A to C, and E and F) and anti-E-cadherin (D) antibodies, and were colored with aminoethylcarbazole (AEC; Dako, Kyoto, Japan). $N=$ nerve; $B r=$ bronchus; $B r l=$ bronchiole; $A l=$ alveolus; and $V=$ blood vessel. ( $G$ to $\mathrm{J}$ ) A section of adult human normal lung tissue from Case 5 was reacted with the anti-TSLC1 antibody and colored with AEC. Bronchiole (G), alveolus (H), bronchiolar gland (I), and funiculus of nerve fibers $(\mathrm{J})$ are shown. All sections were counterstained with hematoxylin. Original magnification, $\times 400$. 
others were negative (data not shown). In addition, the signals were detected at cell-cell boundaries of bronchial and bronchiolar serous gland cells and in and along nerve fibers (Fig. 2, J and I). Similar results were obtained when the mouse adult lung was stained with the same antibody (data not shown).

\section{Reduced Expression of TSLC1 in Pulmonary Adenocarcinoma Other than BAC}

We examined whether TSLC1 expression levels were actually reduced in pulmonary adenocarcinoma by Western blot analyses using the anti-TSLC1 antibody. Characteristics of 47 patients are listed in Table 1. All patients underwent complete curative operation at the time of diagnosis and were adequately followed up at the Hyogo Medical Center for Adults in Japan. Resected lung tissues were used for pathologic diagnosis and protein extraction. Protein samples were obtained both from the largest cut surface of each tumor and from a macroscopically normal lung tissue adjacent to each tumor. Expression levels of TSLC1 were comparable in all noncancerous lung samples (Fig. 3A; data not shown). Thus, expression levels of TSLC1 in individual tumors were compared with the level in a representative noncancerous lung sample after the total protein amounts loaded per lane were equalized by the band intensities for $\alpha$-tubulin. According to the TSLC1 expression level, each tumor was judged either decreased or nondecreased. Nineteen (40\%) tumors expressed decreased levels of TSLC1, and tumors of the rest expressed nondecreased levels (Fig. 3B).

We noticed that the expression profiles of TSLC1 had a significant relation to histologic subtypes. Tumors examined were classified into four histologic subtypes: 15 papillary, 16 BAC, 4 solid, and 12 mixed subtypes. All $(100 \%, 16$ of 16) BAC were judged nondecreased, whereas more than half $(63 \%, 19$ of 31) of adenocarcinomas of other subtypes were judged decreased ( $p<0.0001$ ) (Fig. 3B; Table 1). On the other hand, there was no significant difference in age, gender, pathologic stages, or grade of tumor differentiation between the decreased and nondecreased groups.

Tumors judged nondecreased 16 BAC, 6 adenocarcinomas with mixed subtypes, 5 papillary, and 1 solid adenocarcinomas were further examined by immunohistochemistry using the anti-TSLC1 antibody. In all BAC, signals specific for TSLC1 were clearly detectable on the lateral plasma membranes of BAC cells (Fig. 4, A and B). Intensity and subcellular localization of TSLC1 signals in BAC cells were quite similar to those in bronchiolar and alveolar epithelial cells. In all papillary adenocarcinomas and three adenocarcinomas with mixed subtypes, TSLC1 signals were detected exclusively in tumor cells of lepidic growth components (Fig. 4, C and D). In four of the rest, TSLC1 staining occurred in part of tumor cells of acinar and solid components (Fig. 4, E and F). Even in tumor cells other than BAC cells, TSLC1 signals were detected primarily on lateral plasma membranes. The major components that contained TSLC1 signals are shown in Table 1.

\section{Discussion}

We detected TSLC1 expression in epithelial cells of the lung buds at 10.5 days pc. Because the lung buds first became recognizable around 9.5 days pc and the main bronchi appear in the lung buds by 10 days pc (Kaufman, 1992), our observation indicates that lung epithelial cells start to express TSLC1 at a very early stage of their development. Although TSLC1 expression was detectable in the lung tissues at all ages examined, expression levels and the extent of glycosylation of TSLC1 proteins were changed with age. Moreover, there was a substantial difference in TSLC1 expression pattern among the bronchi, bronchioles, and alveoli as revealed in mouse embryos of late gestational stages (Fig. 2, C, E, and F). Expression of TSLC1 proteins appeared to be regulated in a spatiotemporal manner during lung development.

In mouse and human lungs, TSLC1 was expressed mainly by epithelial cells and localized on their lateral plasma membranes, consistent with recent characterization of this protein as an intercellular adhesion molecule (Ito et al, 2003; Masuda et al, 2002). This localization of TSLC1 proteins in mouse embryonic bronchiolar epithelia was quite similar to that of E- and P-cadherins (Fig. 2D) (Hirai et al, 1989). Cadherins are a family of adhesion molecules that bind homophilically and mediate cell-cell interactions (Takeichi, 1991). E- and P-cadherins play a synergistic role in the organization of epithelial cells during lung morphogenesis (Hirai et al, 1989). By analogy, TSLC1 may have a similar role in developing lungs. In adult lungs, bronchiolar and alveolar epithelial cells and serous gland cells expressed TSLC1 proteins on their lateral plasma membranes, suggesting a physiologic role for TSLC1 in cell-cell interactions. In addition, TSLC1 signals were detectable in and along nerve fibers. Among members of the cadherin family, $\mathrm{N}$-cadherin is preferentially expressed by nerve cells (Takeichi, 1991). Although TSLC1 and cadherin are structurally different from each other, both may function cooperatively in certain cell types.

Expression of TSLC1 was often reduced or lost in pulmonary adenocarcinomas, supporting the hypothesis that this protein is a tumor suppressor of NCSLC. But this hypothesis appeared to be applicable to adenocarcinomas other than BAC, because expression levels of TSLC1 were not reduced in all BAC when compared with those in normal lung tissues. Moreover, subcellular localization of TSLC1 proteins in BAC cells was quite similar to that in bronchiolar and alveolar epithelial cells, indicating that the integrity of TSLC1 was preserved in BAC cells. The integrity of TSLC1 appeared to be preserved also in tumor cells of lepidic growth component of adenocarcinomas other than BAC. Like BAC cells, tumor cells in this component proliferate in a lepidic growth pattern. Although lepidic growth has long been regarded as an alignment of tumor cells along almost intact alveolar walls 
Table 1. Clinical Features and TSLC1 Expression Profiles of 47 Patients with Pulmonary Adenocarcinoma

\begin{tabular}{|c|c|c|c|c|c|c|c|c|c|}
\hline \multirow{2}{*}{$\begin{array}{c}\text { Case } \\
\text { no. }\end{array}$} & \multirow[b]{2}{*}{ Age/sex } & \multicolumn{3}{|c|}{$\mathrm{TNM}^{a}$} & \multirow{2}{*}{$\begin{array}{l}\text { Pathologic } \\
\text { stage }^{b}\end{array}$} & \multirow{2}{*}{$\begin{array}{l}\text { Histologic } \\
\text { subtype }\end{array}$} & \multirow{2}{*}{$\begin{array}{l}\text { Differentiation } \\
\text { grade }\end{array}$} & \multicolumn{2}{|c|}{ TSLC1 expression ${ }^{c}$} \\
\hline & & pT & pN & $\mathrm{M}$ & & & & Level & Component $^{d}$ \\
\hline 1 & $56 / F$ & 1 & 0 & 0 & I & BAC & & $\mathrm{N}$ & Lepidic \\
\hline 2 & $58 / F$ & 1 & 0 & 0 & I & BAC & & N & Lepidic \\
\hline 3 & $74 / \mathrm{F}$ & 1 & 0 & 0 & I & $\mathrm{BAC}$ & & $\mathrm{N}$ & Lepidic \\
\hline 4 & $61 / M$ & 1 & 0 & 0 & I & BAC & & $\mathrm{N}$ & Lepidic \\
\hline 5 & $56 / F$ & 1 & 0 & 0 & I & BAC & & N & Lepidic \\
\hline 6 & $69 / F$ & 1 & 0 & 0 & I & BAC & & N & Lepidic \\
\hline 7 & $74 / F$ & 1 & 0 & 0 & I & BAC & & $\mathrm{N}$ & Lepidic \\
\hline 8 & $62 / F$ & 1 & 0 & 0 & I & BAC & & N & Lepidic \\
\hline 9 & $40 / \mathrm{F}$ & 1 & 0 & 0 & I & $\mathrm{BAC}$ & & N & Lepidic \\
\hline 10 & $62 / F$ & 2 & 1 & 0 & II & BAC & & $\mathrm{N}$ & Lepidic \\
\hline 11 & $71 / \mathrm{M}$ & 2 & 0 & 0 & II & $\mathrm{BAC}$ & & N & Lepidic \\
\hline 12 & $71 / \mathrm{M}$ & 1 & 1 & 0 & II & $\mathrm{BAC}$ & & $\mathrm{N}$ & Lepidic \\
\hline 13 & $59 / F$ & 1 & 1 & 0 & II & $\mathrm{BAC}$ & & N & Lepidic \\
\hline 14 & $63 / \mathrm{M}$ & 2 & 1 & 0 & II & BAC & & $\mathrm{N}$ & Lepidic \\
\hline 15 & $55 / \mathrm{M}$ & 2 & 2 & 0 & $\mathrm{III}_{\mathrm{A}}$ & BAC & & $\mathrm{N}$ & Lepidic \\
\hline 16 & $78 / \mathrm{M}$ & 4 & 1 & 0 & \|\|$_{B}^{A}$ & BAC & & N & Lepidic \\
\hline 17 & $52 / M$ & 1 & 1 & 0 & II & Papillary & Well & $\mathrm{N}$ & Lepidic \\
\hline 18 & $72 / F$ & 2 & 1 & 0 & II & Papillary & Well & N & Lepidic \\
\hline 19 & $67 / M$ & 2 & 2 & 0 & $\| I_{A}$ & Papillary & Well & D & \\
\hline 20 & $74 / M$ & 2 & 2 & 0 & \|\|$_{A}$ & Papillary & Well & D & \\
\hline 21 & $73 / F$ & 2 & 2 & 0 & \|\|$_{A}^{A}$ & Papillary & Well & $\mathrm{N}$ & Lepidic \\
\hline 22 & $82 / M$ & 2 & 2 & 0 & $\| I_{A}$ & Papillary & Well & D & \\
\hline 23 & $37 / M$ & 1 & 2 & 0 & \|\|$_{A}^{A}$ & Papillary & Well & D & \\
\hline 24 & $67 / M$ & 1 & 2 & 0 & \|\|$_{A}^{A}$ & Papillary & Moderate & D & \\
\hline 25 & $54 / M$ & 4 & 2 & 0 & \|\|$_{B}$ & Papillary & Well & D & \\
\hline 26 & 79/M & 4 & $X^{e}$ & 0 & \|\|$_{B}$ & Papillary & Well & $\mathrm{N}$ & Lepidic \\
\hline 27 & $74 / \mathrm{M}$ & 4 & 2 & 0 & $\mathrm{III}_{\mathrm{B}}$ & Papillary & Well & $D$ & \\
\hline 28 & $53 / F$ & 4 & 2 & 0 & \|\|$_{B}$ & Papillary & Moderate & D & \\
\hline 29 & $62 / F$ & 2 & 2 & 1 & IV & Papillary & Well & $\mathrm{N}$ & Lepidic \\
\hline 30 & $75 / \mathrm{M}$ & 2 & 2 & 1 & IV & Papillary & Moderate & D & \\
\hline 31 & $69 / \mathrm{M}$ & 3 & 0 & 1 & IV & Papillary & Poor & D & \\
\hline 32 & $53 / \mathrm{F}$ & 1 & 0 & 0 & I & Solid & Poor & D & \\
\hline 33 & $73 / \mathrm{M}$ & 1 & 0 & 0 & I & Solid & Poor & D & \\
\hline 34 & $60 / \mathrm{M}$ & 3 & 0 & 0 & II & Solid & Poor & $\mathrm{N}$ & Solid \\
\hline 35 & $55 / \mathrm{M}$ & 2 & 1 & 0 & II & Solid & Poor & $D$ & \\
\hline 36 & $62 / \mathrm{M}$ & 2 & 0 & 0 & I & Mixed & Moderate & $\mathrm{N}$ & Lepidic \\
\hline 37 & $68 / \mathrm{M}$ & 2 & 0 & 0 & I & Mixed & Poor & $D$ & \\
\hline 38 & $70 / \mathrm{M}$ & 1 & 0 & 0 & I & Mixed & Poor & $\mathrm{N}$ & Acinar \\
\hline 39 & $63 / \mathrm{M}$ & 2 & 0 & 0 & I & Mixed & Poor & $D$ & \\
\hline 40 & $45 / F$ & 4 & 1 & 0 & II & Mixed & Well & $\mathrm{N}$ & Lepidic \\
\hline 41 & $52 / \mathrm{M}$ & 2 & 1 & 0 & II & Mixed & Poor & D & \\
\hline 42 & $73 / F$ & 1 & 1 & 0 & II & Mixed & Poor & D & \\
\hline 43 & $72 / F$ & 1 & 1 & 0 & II & Mixed & Poor & $\mathrm{N}$ & Solid \\
\hline 44 & $77 / \mathrm{M}$ & 3 & 0 & 0 & II & Mixed & Poor & $\mathrm{N}$ & Lepidic \\
\hline 45 & $68 / F$ & 1 & 2 & 0 & II & Mixed & Moderate & $D$ & \\
\hline 46 & $71 / \mathrm{M}$ & 2 & 2 & 0 & $\| I_{A}$ & Mixed & Poor & $\mathrm{N}$ & Acinar \\
\hline 47 & $72 / F$ & 4 & 1 & 0 & \|\|$_{B}$ & Mixed & Poor & $D$ & \\
\hline
\end{tabular}

BAC, bronchioloalveolar carcinoma; D, decreased; F, female; M, male; N, nondecreased; TNM, tumor, node, metastasis; TSLC1, tumor suppressor in lung cancer-1.

${ }^{a}$ The anatomic extent of the tumors were assessed by the TNM system: increasing size of primary tumor as T1, T2, T3, or T4; advancing nodal disease as N0, $\mathrm{N} 1$, or N2; and the absence or presence of metastases as M0 or M1, respectively.

${ }^{b}$ Stage grouping of the TNM subsets was according to the International System for Staging Lung Cancer: stage I, T1N0M0 and T2N0M0; stage II, T1N1M0, T2N1M0, and T3N0M0; stage III $\mathrm{A}_{\mathrm{A}}$, T3N1M0, T1N2M0, T2N2M0, and T3N2M0; stage III , T4 any N M0, and any T N3M0; and stage IV, any T any N M1.

${ }^{c}$ A summary of the results obtained by Western blot and immunohistochemical analyses in the present study.

${ }^{d}$ Tumors judged nondecreased were subjected to immunohistochemistry, and the major histologic components that contained TSLC1 signals are shown.

${ }^{e}$ Regional lymph nodes cannot be assessed.

(Miller, 1990; Travis et al, 1988), the molecular bases underlying lepidic growth are not fully understood. Ohori et al (1996) showed that BAC cells expressed relatively high levels of an isoform of the CD44 transmembrane glycoprotein. Koga et al (2001) reported that p53 mutation is of rare occurrence in BAC cells. 

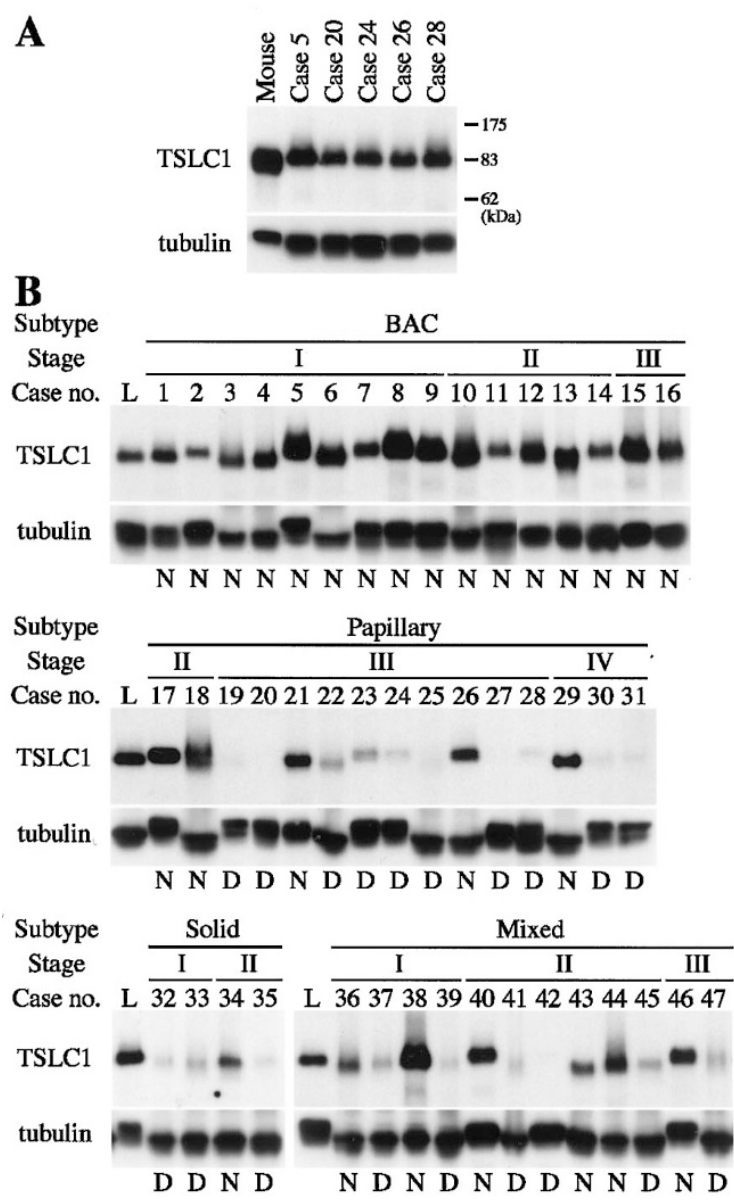

Figure 3.

Western blot analyses of TSLC1 in adult human normal lung tissues and pulmonary adenocarcinomas. Protein samples were subjected to electrophoresis on $10 \%$ SDS-polyacrylamide gels and blotted with the anti-TSLC1 antibody. After stripping, the blots were probed again with the anti- $\alpha$-tubulin antibody to indicate the total amount of proteins loaded per lane. (A) Western blot analyses of TSLC1 in normal lung tissues from adult mice and five patients (Cases 5, 20, 24, 26, and 28). (B) Western blot analyses of TSLC1 in pulmonary adenocarcinomas of various histologic subtypes. Histologic subtypes, pathologic stages (I, II, III, and IV), and case numbers are shown above lanes. According to the relative TSLC1 signal intensity, each tumor was judged either nondecreased $(M)$ or decreased $(D)$, as indicated below each lane. The criteria for this judgement are described in the "Western Blot Analysis" section. Lysate $(L)$ of normal lung tissue from Case 24 that was loaded in the left-most lane as a positive control is shown.

Kumaki et al (2001) showed that the integrity of type-IV collagen is preserved in lepidic growth component of pulmonary adenocarcinoma. Preservation of the integrity of TSLC1 appeared to be another molecular event that defines lepidic growth tumor cells and might help to prevent tumor cells from invading alveolar walls.

In some adenocarcinomas other than BAC, TSLC1 staining occurred in part of tumor cells present in acinar and solid components. Although we cannot point out any difference between TSLC1-positive and -negative tumor cells in these tumors at present, TSLC1-positive cells may be kept less invasive by preserving the integrity of TSLC1. Future follow-up of the patients examined in this study may reveal some relationship between TSLC1 expression and prognosis in adenocarcinomas other than BAC.

In conclusion TSLC1 expression was regulated spatiotemporally during lung development, and the protein was primarily detected on lateral plasma membranes of bronchiolar and alveolar epithelial cells, suggesting a role for TSLC1 in interactions of these cells. Expression of TSLC1 proteins was often reduced or lost in pulmonary adenocarcinomas other than BAC. Not only BAC cells but also tumor cells of lepidic growth components of other adenocarcinomas expressed TSLC1 on their lateral plasma membranes as did bronchiolar and alveolar epithelial cells. These results not only support the hypothesis that TSLC1 is a tumor suppressor of NSCLC, but also suggest that preserved integrity of TSLC1 may underlie unique clinicopathologic features of BAC, such as lepidic growth of tumor cells and a better outcome of surgical treatment.

\section{Materials and Methods}

\section{Patients and Classification of Tumors}

All patients examined in this study underwent a standard operation, which included the complete dissection of the first and second groups of the regional lymph nodes, at Hyogo Medical Center for Adults in Japan from 2000 to 2002. They were never treated with chemotherapy or irradiation before surgery. All cancer lesions appeared to have originated from peripheral areas of the lungs and were fully resectable. The patients consisted of 27 men and 20 women, and their mean age was 64.5 years (range, 37 to 82 years). Clinical and pathologic data on these patients are summarized in Table 1. The anatomic extent of tumors was assessed by the tumor, node, metastasis (TNM) system, in which the T, N, and $\mathrm{M}$ categories indicate the status of primary tumor, regional lymph node, and distant metastasis, respectively (Mountain, 1997). The three categories were then clustered according to the International Staging System for Lung Cancer (Mountain, 1997) to determine the pathologic stages of the tumors. Histologic types and differentiation grades of the tumors were based on the 1999 WHO classification (Travis et al, 1999) and the criteria of the Japan Lung Cancer Association (Kobayashi, 1999), respectively.

\section{Preparation of Tissues and Antibodies}

Tissues were obtained both from the largest cut surface of each tumor and from a macroscopically normal lung tissue adjacent to each tumor. The tissues were divided longitudinally into two: one was used for protein analysis, and the other was used for histologic study. Mice (C56BL/6) were purchased from Japan SLC (Hamamatsu, Japan). Mouse embryos and adult lungs were longitudinally cut into two and used similarly.

Rabbits were immunized against the synthetic polypeptide containing 15 amino acids of the C-terminus of SgIGSF, a mouse orthologue of TSLC1 (Wakayama et al, 2001). Four months later, the rabbit 


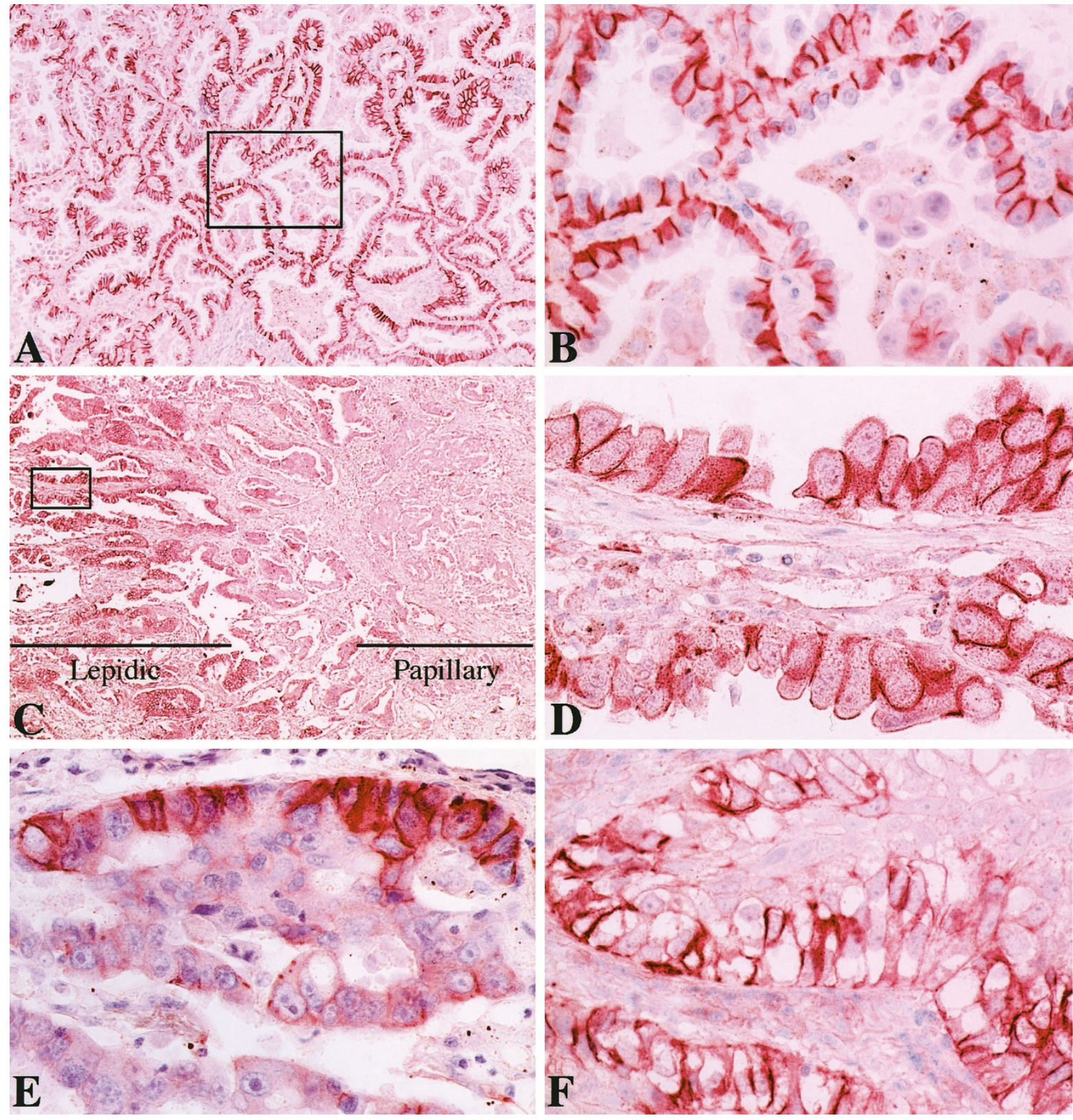

\section{Figure 4.}

Immunohistochemical staining of TSLC1 in pulmonary adenocarcinomas. Sections of BAC (Case 15; A and B), papillary adenocarcinoma (Case 17; C and D), and adenocarcinoma with mixed subtypes (Cases 38 and 43; E and F) were reacted with the anti-TSLC1 antibody and colored with aminoethylcarbazole . All sections were counterstained with hematoxylin. B and D show high-power field images of the areas encircled by bold lines in A and C. Note that TSLC1 signals are detectable in the left half (corresponding to the lepidic growth component) but not in the right half (corresponding to the papillary component) of papillary adenocarcinoma (Case 17). Original magnification: $A(\times 100)$; $B, D, E$, and $F(\times 400)$; and $C(\times 40)$.

sera were purified with an affinity column containing the synthetic polypeptide and were used as an antiTSLC1 antibody in the present study, because the amino acid sequence of the C-terminus of SgIGSF was the same as that of TSLC1. The method of preparation and the sensitivity of the antibody were described in detail previously (Ito et al, 2003; Wakayama et al, 2003).

\section{Immunohistochemistry}

Tissues were fixed with $4 \%$ paraformaldehyde, embedded in paraffin, and cut into sections (4- $\mu \mathrm{m}$ thick).
Sections were deparaffinized, rehydrated, autoclaved for 20 minutes at $121^{\circ} \mathrm{C}$ in $10 \mathrm{~mm}$ citrate buffer solution ( $\mathrm{pH} 6.0)$, and incubated in methanol containing $0.3 \%$ peroxide for 30 minutes. Sections were washed three times with PBS (PBS) prior to each step of the procedure. The sections were incubated in PBS containing $2 \%$ BSA for 30 minutes to block nonspecific Ig binding. Subsequently the sections were incubated with the anti-TSLC1 antibody (1:500 dilution) in PBS containing $2 \%$ BSA for 6 hours at $4^{\circ} \mathrm{C}$, and were incubated with a biotin-conjugated antirabbit Ig $G$ antibody (1:100 dilution; MBL, Nagoya, Japan) in PBS 
containing $2 \%$ BSA for 2 hours at $4^{\circ} \mathrm{C}$. The sections were then incubated with peroxidase-conjugated streptavidin (1:400 dilution; Dako, Kyoto, Japan) for 30 minutes at room temperature. After three washes with PBS, the color was developed using aminoethylcarbazole (AEC; Dako, Kyoto, Japan) as a substrate for peroxidase. Finally the tissues were counterstained with hematoxylin and mounted. For E-cadherin staining, a monoclonal anti-E-cadherin antibody (clone 36; Transduction Laboratories, Lexington, Kentucky) and a biotin-conjugated antimouse Ig $\mathrm{G}$ antibody (MBL) were used as a primary and a secondary antibody, respectively. Negative immunohistochemical control procedures included omission of the primary antibodies and replacement of the primary antibodies by normal rabbit or mouse Ig $\mathrm{G}$ in appropriate concentrations. These control procedures gave negative results.

\section{Western Blot Analysis}

Tissues frozen in liquid nitrogen were crushed into pieces and vigorously vortexed in a buffer solution containing $50 \mathrm{~mm}$ Tris- $\mathrm{HCl}$ (pH 8.0), $150 \mathrm{~mm} \mathrm{NaCl}, 1 \%$ Triton X-100, and $1 \mathrm{~mm}$ phenylmethylsulfonyl fluoride. Impurities were removed by centrifugation. The resulting lysates were separated on $10 \%$ SDSpolyacrylamide gels and transferred to Immobilon (Millipore, Bedford, Massachusetts). The blots were reacted with the anti-TSLC1 antibody (1:500 dilution) in a buffer containing $20 \mathrm{~mm}$ Tris- $\mathrm{HCl}$ (pH 8.0), $150 \mathrm{~mm}$ $\mathrm{NaCl}, 0.05 \%$ Triton $\mathrm{X}-100$, and 5\% skim milk (Difco, Sparks, Maryland) for 3 hours at $4^{\circ} \mathrm{C}$. After washing, the blots were incubated with a peroxidaseconjugated antirabbit Ig $\mathrm{G}$ antibody in a buffer containing $20 \mathrm{~mm}$ Tris- $\mathrm{HCl}$ ( $\mathrm{pH} 8.0$ ), $150 \mathrm{~mm} \mathrm{NaCl,} \mathrm{0.05 \%}$ Triton $\mathrm{X}-100$, and $5 \%$ skim milk for 2 hours at $4^{\circ} \mathrm{C}$, and then reacted with Western Lighting reagents (PerkinElmer Life Sciences, Boston, Massachusetts) before exposure. After stripping, the blots were incubated firstly with an anti- $\alpha$-tubulin antibody (Sigma, St. Louis, Missouri) and secondarily with a peroxidase-conjugated antimouse Ig $\mathrm{G}$ antibody (MBL), and then were reacted with Western Lighting reagents (PerkinElmer) before exposure.

Chemiluminescent intensities of specific signals were calculated with the FluorChem IS-8000 system (Alpha Innotech Corporation, San Leandro, California). Relative TSLC1 signal intensities were obtained by dividing intensities of TSLC1 signals by those of $\alpha$-tubulin signals. When a relative TSLC1 signal intensity in a tumor was half of that in a normal lung tissue or larger, the tumor was judged nondecreased. Tumors, to which this criterion was not applicable, were judged decreased.

\section{Enzymatic Digestion of N-linked Glycosylation}

Protein samples of lung tissues were deglycosylated with PNGase F (New England Biolabs, Beverly, Massachusetts) according to the manufacturer's instructions. Briefly, a $100-\mu$ l volume of lung tissues frozen in liquid nitrogen was crushed into pieces, vigorously vortexed in the denaturing buffer supplied with the enzyme, and incubated at $100^{\circ} \mathrm{C}$ for 10 minutes. Then one-fiftieth of the sample was incubated at $37^{\circ} \mathrm{C}$ for 1 hour in the presence of PNGase F (500 units). The samples were then separated on SDS-polyacrylamide gels and reacted with the anti-SgIGSF antibody as described in the "Western Blot Analysis" section above.

\section{Statistical Analysis}

The $\chi^{2}$ test was performed using StatView (Abacus Concepts Inc., Cary, North Carolina) software on a Macintosh computer. A $p$ value of $<0.05$ was considered to be significant.

\section{Acknowledgement}

We thank Dr. Keisuke Hanioka (Hyogo Medical Center for Adults) and Dr. Chiho Oobayashi (Kobe University Medical School) for pathologic classification, and Mr. Masaharu Kohara (Osaka University Medical School) for technical assistance.

\section{References}

Breathnach OS, Ishibe N, Williams J, Linnoila RI, Caporaso $\mathrm{N}$, and Johnson BE (1999). Clinical features of patients with stage IIIB and IV bronchioloalveolar carcinoma of the lung. Cancer 86:1165-1173.

Fukami T, Satoh H, Fujita E, Maruyama T, Fukuhara $H$, Kuramochi M, Takamoto S, Momoi T, and Murakami $\mathrm{Y}$ (2002). Identification of the Tslc1 gene, a mouse orthologue of the human tumor suppressor TSLC1 gene. Gene 295:712.

Grover FL and Piantadosi S (1989). Recurrence and survival following resection of bronchioloalveolar carcinoma of the lung-the Lung Cancer Study Group experience. Ann Surg 209:779-790.

Hirai Y, Nose A, Kobayashi S, and Takeichi M (1989). Expression and role of $\mathrm{E}$ - and $\mathrm{P}$-cadherin adhesion molecules in embryonic histogenesis. I. Lung epithelial morphogenesis development 105:263-270.

Ito A, Jippo T, Wakayama T, Morii E, Koma $Y$, Onda $H$, Nojima H, Iseki S, and Kitamura $Y$ (2003). SgIGSF: A new mast-cell adhesion molecule used for attachment to fibroblasts and transcriptionally regulated by MITF. Blood 101: 2601-2608.

Kaufman MH (1992). The Atlas of Mouse Development. London: Academic Press Ltd., 445-448.

Kobayashi Y (1999). Histology classification, 5th ed. In: The Lung Cancer Association, editors. General rule for clinical and pathological record of lung cancer. Tokyo: Kanehara Shuppan Co., 92-106.

Koga T, Hashimoto S, Sugio K, Yoshino I, Mojtahedzadeh S, Matsuo Y, Yonemitsu Y, Sugimachi K, and Sueishi K (2001). Clinicopathological and molecular evidence indicating the independence of bronchioloalveolar components from other subtypes of human peripheral lung adenocarcinoma. Clin Cancer Res 7:1730-1738. 
Kumaki F, Matsui K, Kawai T, Ozeki Y, Yu Z-X, Ferrans VJ, and Travis WD (2001). Expression of matrix metalloproteinases in invasive pulmonary adenocarcinoma with bronchioloalveolar component and atypical adenomatous hyperplasia. Am J Pathol 159:2125-2135.

Kuramochi M, Fukuhara H, Nobukuni T, Kanbe T, Maruyama T, Ghosh HP, Pletcher M, Isomura M, Onizuka M, Kitamura T, Sekiya T, Reeves $\mathrm{RH}$, and Murakami $\mathrm{Y}$ (2001). TSLC1 is a tumor suppressor gene in human non-small-cell lung cancer. Nat Genet 27:427-430.

Kuriyama K, Seto M, Kasugai T, Higashiyama M, Kido S, Sawai Y, Kodama K, and Kuroda C (1999). Ground-glass opacity on thin-section CT: Value in differentiating subtypes of adenocarcinomas of the lung. Am J Roentgenol 173:465469.

Kwiatkowski D, Harpole D, Godleski J, Herdon JE, Shieh DB, Richards W, Blanco R, Xu HJ, Strauss GM, and Sugarbaker DJ (1998). Molecular pathologic substaging in 244 stage I non-small-cell lung cancer patients: Clinical implications. $\mathrm{J}$ Clin Oncol 16:2468-2477.

Masuda M, Yageta M, Fukuhara H, Kuramochi M, Maruyama T, Nomoto A, and Murakami Y (2002). The tumor suppressor protein TSLC1 is involved in cell-cell adhesion. J Biol Chem 277:31014-31019.

Miller RR (1990). Bronchioloalveolar cell adenomas. Am J Surg Pathol 14:904-912.

Mountain CF (1997). Revisions in the international system for staging lung cancer. Chest 111:1710-1717.

Murakami Y (2002). Functional cloning of a tumor suppressor gene, TSLC1, in human non-small cell lung cancer. Oncogene 21:6936-6948.

Ohori NP, Coppola D, and Landreneau RJ (1996). CD44v6 expression in primary bronchioloalveolar carcinoma and conventional pulmonary adenocarcinoma. Mod Pathol 9:507512.
Silver SA and Askin FB (1997). True papillary carcinoma of the lung: A distinct clinicopathologic entity. Am J Surg Pathol 21:43-51.

Takeichi M (1991). Cadherin cell adhesion receptors as a morphogenetic regulator. Science 251:1451-1455.

Travis WD, Colby TV, Corrin B, Shimosato Y, and Brambilla E (1999). Histologic typing of lung and pleural tumors. In: World Health Organization international histological classification of tumors. Berlin: Springer.

Travis WD, Linnoila RI, Horowitz M, Becker RL Jr, Pass $H$, Ozols R, and Gazdar A (1988). Pulmonary nodules resembling bronchioloalveolar carcinoma in adolescent cancer patients. Mod Pathol 1:372-377.

Wakayama T, Koami H, Ariga H, Kobayashi D, Sai Y, Tsuji A, Yamamoto M, and Iseki S (2003). Expression and functional characterization of the adhesion molecule spermatogenic immunoglobulin superfamily (SgIGSF) in the mouse testis. Biol Reprod 68:1755-1763.

Wakayama T, Ohashi K, Mizuno K, and Iseki S (2001). Cloning and characterization of a novel mouse immunoglobulin superfamily gene expressed in early spermatogenic cells. Mol Reprod Dev 60:158-164.

Yageta M, Kuramochi M, Masuda M, Fukami T, Fukuhara $H$, Maruyama T, Shibuya M, and Murakami Y (2002). Direct Association of TSLC1 and DAL-1, two distinct tumor suppressor proteins in lung cancer. Cancer Res 62:5129-5133.

Yokose T, Suzuki K, Nagai K, Nishiwaki Y, Sasaki S, and Ochiai A (2000). Favorable and unfavorable morphologic prognostic factors in peripheral adenocarcinoma of the lung $3 \mathrm{~cm}$ or less in diameter. Lung Cancer 29:179-188. 